\title{
Endoscopic hemostasis with hemoclips for active gastric variceal bleeding
}

A 53-year-old woman was transferred by ambulance to our institution because of hematemesis. Her medical history included alcoholic cirrhosis with no regular medical follow-up or treatment. Emergency esophagogastroduodenoscopy (EGD) identified a "bleeding jet" from isolated gastric varices in the fundus ( $\bullet$ Fig. 1).

Hemostasis was immediately achieved with a hemoclip ( Fig. 2), and finally a total of eight hemoclips were applied to prevent re-bleeding.

The patient had no hematemesis thereafter, and EGD on day 4 after admission revealed that four hemoclips remained on the varices ( Fig. 3 ).

On day 16 after admission, balloon-occluded retrograde transvenous obliteration (BRTO) was carried out successfully to eradicate the gastric varices. At 2 months, the gastric varices had decreased markedly in size ( Fig. 4).

It is recommended that bleeding from gastric fundal varices is treated by endoscopic variceal obliteration using tissue adhesives, where available, otherwise, endoscopic variceal ligation is an option $[1,2]$. Endoscopic ligation, however, can cause larger and deeper ulcers and is associated with higher rates of secondary bleeding in comparison with cyanoacrylate injection or sclerotherapy [2,3]. We have applied hemoclips to arrest bleeding when injection therapy has been unavailable in an emergency setting. Mechanical therapy using hemoclips can approximate the two sides of a bleeding vessel immediately, definitively, and securely, thus occluding it and stopping the bleeding. It is also theoretically advantageous in patients who have coagulopathy because it provides direct occlusion of a bleeding vessel. Furthermore, as hemoclips are made of steel, they do not elicit an inflammatory reaction. Hemoclips generally fall off at 10-14 days after deployment, after the lesion has partly healed and when it is unlikely to re-bleed [4]. However, hemoclips may dislodge spontaneously within a day of application, thus limiting their efficacy. Therefore, even if a bleeding site is successfully closed with the first clip, additional hemoclips should be deployed to ensure secure closure. Using this approach, the gastric varices in our present

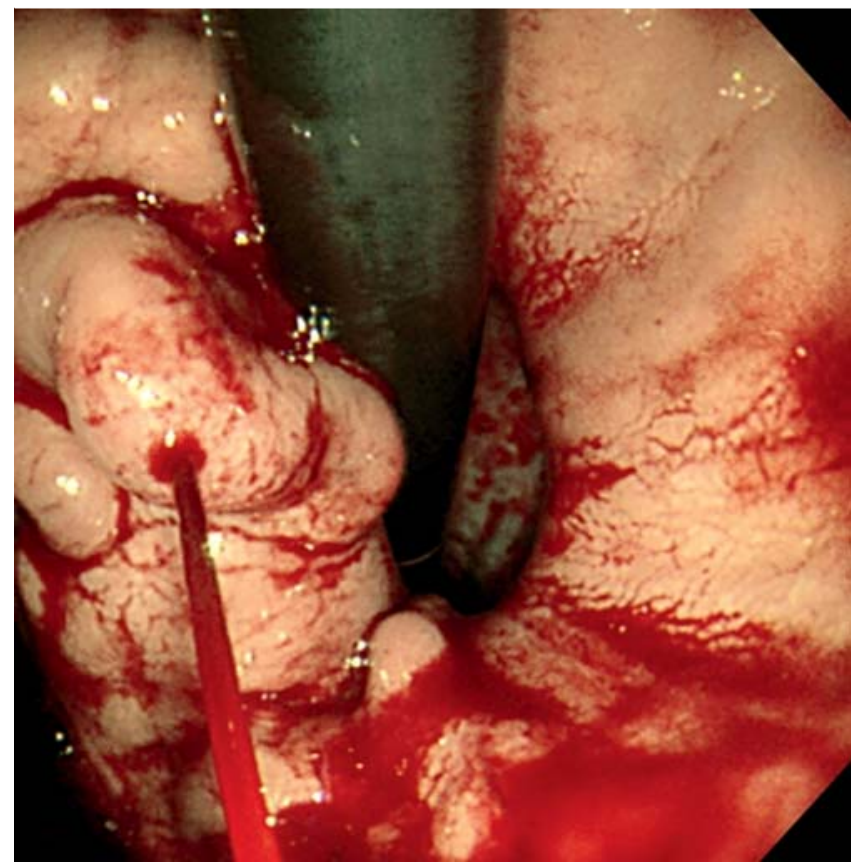

Fig. 1 A "bleeding jet" from the gastric varices clearly identified at endoscopy.

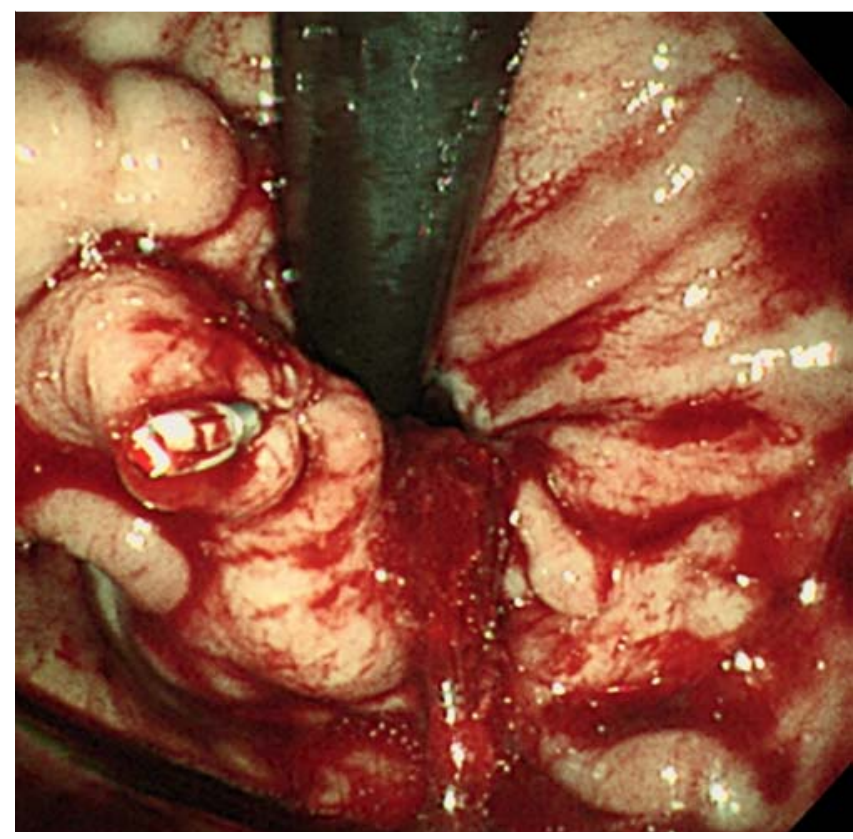

Fig. 2 The active gastric variceal bleeding was immediately arrested after application of the first hemoclip. 


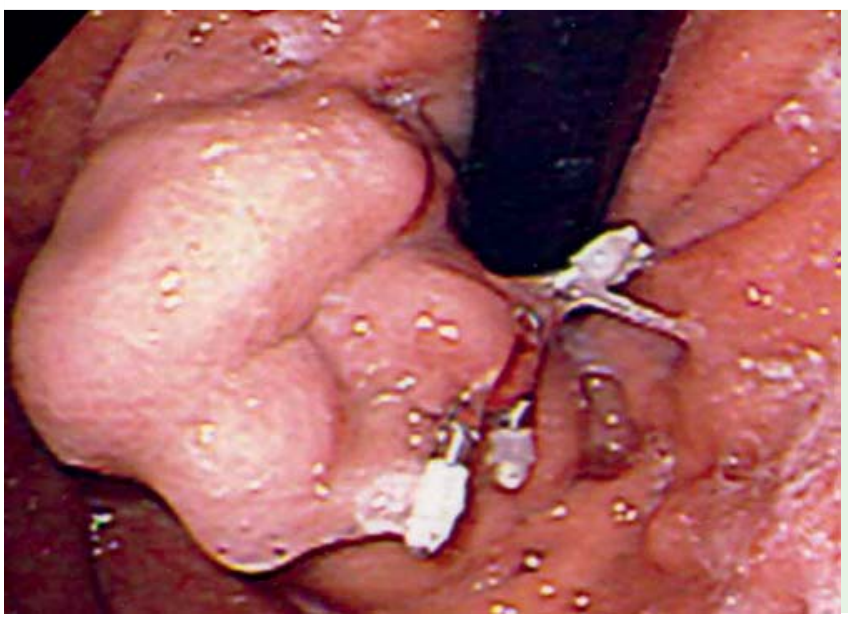

Fig. 3 A total of four hemoclips were found to have remained on the gastric varices during a second-look esophagogastroduodenoscopy (EGD) on day 4 after admission; no active bleeding or blood clot was identified in the stomach.

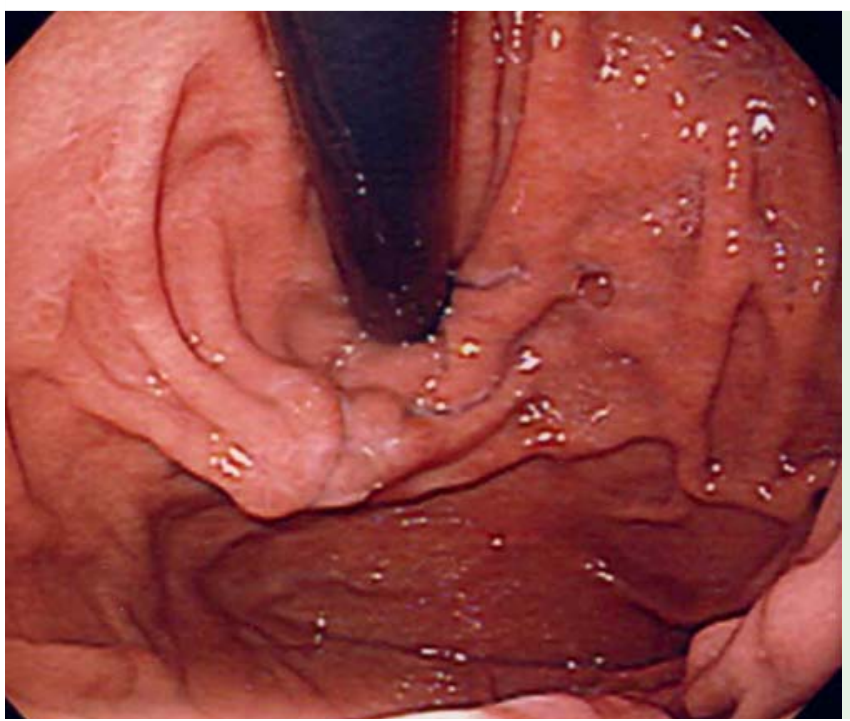

Fig. 4 At follow-up esophagogastroduodenoscopy (EGD) 2 months later, the gastric varices had decreased markedly in size, and no hemoclip was found.

case could be successfully eradicated by elective BRTO. On reviewing the English literature, we found only one similar case, which was at first successfully treated by a hemoclip and the varices subsequently eradicated with injection of cyanoacrylate [5].

\section{Competing interests: None}

Endoscopy_UCTN_Code_TTT_1AO_2AD
T. Morimoto ${ }^{1}$, K. I. Fu' ${ }^{1}$, H. Konuma ${ }^{1}$, Y. Izumi ${ }^{1}$, A. Asano ${ }^{2}$, S. Kokubu ${ }^{1}$, A. Miyazaki ${ }^{1}$, S. Watanabe ${ }^{3}$

1 Department of Gastroenterology, Juntendo University Nerima Hospital, Tokyo, Japan

2 Department of Gastroenterology, Ogikubo Hospital, Tokyo, Japan

3 Department of Gastroenterology, Juntendo University School of Medicine, Tokyo, Japan

\section{References}

1 Tripathi D, Hayes PC. Endoscopic therapy for bleeding gastric varices: to clot or glue? Gastrointest Endosc 2008; 68: 883-886

2 Lee MS, Cho JY, Cheon YK et al. Use of detachable snares and elastic bands for endoscopic control of bleeding from large gastric varices. Gastrointest Endosc 2002; 56: 83-88

3 Jutabha R, Jensen DM, Egan J et al. Randomized, prospective study of cyanoacrylate injection, sclerotherapy, or rubber band ligation for endoscopic hemostasis of bleeding canine gastric varices. Gastrointest Endosc 1995; 41: 201 - 205

4 Shin EJ, Ko CW, Magno P et al. Comparative study of endoscopic clips: duration of attachment at the site of clip application. Gastrointest Endosc 2007; 66: 757 - 761

5 Arantes V, Albuquerque W. Fundal variceal hemorrhage treated by endoscopic clip. Gastrointest Endosc 2005; 61: 732

\section{Bibliography}

DOI $10.1055 / \mathrm{s}-0030-1255942$

Endoscopy 2010; 42: E333 -E334

(c) Georg Thieme Verlag KG Stuttgart · New York . ISSN 0013-726X

\section{Corresponding author \\ K. I. Fu}

Department of Gastroenterology Juntendo University Nerima Hospital 3-1-10 Nerimatakanodai

\section{Nerima}

Tokyo 177-0033

Japan

Fax: +81-3-5923-3111

fukuangi@hotmail.com 